\title{
CFD Simulations of Gas Holdup in a Bubble Column at High Gas Temperature of a Helium-Water System
}

\author{
Mohammed W. Abdulrahman \\ Rochester Institute of Technology \\ Dubai, UAE \\ mwacad@rit.edu
}

\begin{abstract}
Bubble columns (BCs) are systems that contain two-phases; gas, and liquid, in which gaseous bubbles are dispersed through a liquid in a vertical column. They have a wide range of applications because of their many advantages. The hydrodynamics of the BCs have a significant effect on its scale up analysis. The most important parameter that can be used for describing the performance of the BCs is the gas holdup. In this paper, the overall gas holdup was predicted by developing computational fluid dynamics (CFD) simulations for a helium-water bubble column, where helium gas is injected at $90^{\circ} \mathrm{C}$ through a liquid of water at $22^{\circ} \mathrm{C}$. The approaches used to model the bubble column by CFD is 2D plane. From the CFD simulations, it was found that the overall gas holdup increases by increasing the superficial gas velocity at any specific static liquid height. In addition, the overall gas holdup decreases by increasing the static liquid height at any given superficial gas velocity. All CFD simulation results of gas holdup were validated by experimental results of helium-water BCs from previous literature with good agreement, which demonstrates the applicability of the simulations for this kind of BC systems. The CFD results were validated for superficial gas velocities up to $0.15 \mathrm{~m} / \mathrm{s}$, and aspect ratios up to 4 . From the comparison with the experimental results, it was found that in general, the profiles of gas holdup determined from CFD simulations, under-predicted the experimental data. Also, it was shown that the experimental effects of the static liquid height on gas holdup were correctly predicted by CFD simulations. Moreover, it was observed that the distribution of gas holdup along the cross-section of the column is unequal, where the gas holdup is higher at the center of the column and lower near the wall region.
\end{abstract}

Keywords: Bubble column reactors; CFD; Gas holdup; Multi-phase; Hydrodynamics

\section{Introduction}

Bubble columns are used in different industrial applications because of their advantages that motivates doing more detailed studies with this type of reactors. The advantages are; better temperature control; lower pressure drop; and high volumetric heat transfer rates. Additional advantages include; higher values of effective interfacial areas; relatively cheap to construct and operate, require less floor space [1]; and no challenges of material selection for heating jacket or insertions. In spite of the fact that BCs are simple in construction, accurate scale-up of such reactors requires a comprehensive knowledge of the hydrodynamic and heat transfer characteristics at the same conditions of the targeted process [2]. This scale-up generally depends on the evaluation of heat transfer and mixing characteristics, as well as chemical kinetics of the reacting system [3]. The hydrodynamics of the BC have a significant effect on its scale up analysis. In BCs, gas phase that is moving upward transfers momentum to the liquid phase that is either stagnant or moving slower than the gas. Therefore, the hydrodynamics of BCs are controlled mainly by the gas flow [2]. It has been reported that the operating conditions and design as well as the geometry of the column strongly affect the hydrodynamics of the BCs [4-6]. One of the most important hydrodynamic characteristics of the BCs is the gas holdup.

In the literature, there are many studies related to BCs, such as hydrodynamics and flow regimes, as well as design and scale up analyses. Nigar et al. [3] have reviewed bubble column reactors (BCRs) by focusing on the reactor design, fluid dynamics and flow regime transitions of reactors. The most investigated parameter was gas holdup and for gas velocities up to $35 \mathrm{~cm} / \mathrm{s}$ [3]. Behkish [7] has used two BCRs with different diameters to measure the gas holdup for five different gases $\left(\mathrm{N}_{2}, \mathrm{H}_{2}, \mathrm{CO}, \mathrm{He}\right.$ and $\left.\mathrm{CH}_{4}\right)$ in Isopar-M liquid [7]. The data were obtained under wide ranges of pressures (1-27 bar), superficial gas velocities (0.08-0.4 m/s), and temperatures $(323-453 \mathrm{~K})$. Abdulrahman [8-12] has studied experimentally the hydrodynamics and direct contact heat transfer in a SBC with a high temperature helium gas and a slurry of liquid water and alumina solid particles. He has formulated new empirical equations for the gas holdup [8, 12] and the volumetric heat 
transfer coefficient [10-12] in terms of the Reynolds number, reactor dimensions and solid concentration, for both bubbly and churn-turbulent flow regimes.

The modelling by CFD simulation in multiphase flow has been studied by many researchers [13-18]. In the literature, there is no universal agreement that indicates that the CFD models are capable of predicting the experimental results of multiphase flow regimes [18]. For instance, Delnoij et al. [19, 21] have used Eulerian-Lagrangian approach in a flat bubble column to model two-phase flow by using laminar flow model, as well as drag, lift, virtual-mass, and hydrodynamicinteraction forces [22]. Sokolichin and Eigenberger [23] have obtained same results by using finer grid size and neglecting the effects of virtual-mass and lift forces, as well as bubble-bubble interactions. Deen et al. [24] have found that using the virtual mass force will not influence the results. Krishna and Van Baten [25] have studied high pressure turbulent flow simulations and took into consideration the drag force only. They have found that there is high uncertainty when adding the effects of lift forces of small and large bubbles. Moreover, they have noted that there is no effect of the virtual mass force on the results of the simulations. Abdulrahman $[26,27]$ has performed CFD analyses to study the volumetric heat transfer coefficient and the temperature distribution in a direct contact heat transfer for a helium-water-alumina slurry bubble column reactor, where helium gas is injected at $90^{\circ} \mathrm{C}$ through a slurry of water at $22^{\circ} \mathrm{C}$ and alumina solid particles. He has studied the effects of superficial gas velocity, static liquid height, and solid particles concentration, on the volumetric heat transfer coefficient and the temperature distribution of the SBC. The results of CFD simulations were compared with experimental data from previous literature and show that the profiles of the volumetric heat transfer coefficient calculated from CFD models, generally under-predicts the experimental data. The CFD model correctly predicted the experimental effects of static liquid height and solid concentration on volumetric heat transfer coefficient.

Law et al. [28] have determined the average gas holdup by using 2-D and 3-D models for a bubble column. They have examined the influence of various cell resolutions in calculating the average gas holdup by using FLUENT. They have found that there is a good agreement between the 2-D simulations and the experiments of Rampure et al. [29] with a cell size of $0.67 \mathrm{~cm}$. Also, they have reported that if the sizes of the cells are smaller than the size of the bubble, this will lead to unreasonable results. Moreover, they have found that both 3-D and 2-D simulations will predict the same results if their resolutions are comparable. Rampure et al. [29] have investigated the setup of FLUENT by carrying out experiments on a cylindrical column with two and three phase systems to measure gas holdup. They have found that the experimental results were lower than the CFD results and the agreement of the results was acceptable [30]. Krishna et al. [25] have investigated experimentally gas holdups for small and large bubbles with different systems and different column diameters. Also, they have determined the overall gas holdup by using CFD in an Eulerian framework and compared the CFD results with the experimental results for three different column diameters. They have reported that the results were in a good agreement [2].

In this paper, the objective is to study the CFD analyses of the BC from the perspective of hydrodynamics in a steady state condition. The purpose of the numerical works is to develop and validate new predictive CFD models by using the well-known software packages (ANSYS FLUENT). The CFD models will be developed by using two dimensional simulations to predict the values of the gas hold-up at different superficial gas velocities, and static liquid heights.

\section{CFD Simulations of the Multiphase Flow}

As indicated by Abdulrahman [26], the CFD simulations in this paper are performed for a 2D plane and a steady state system with Eulerian-Eulerian model, Eulerian sub-model, and pressure based solver type. The equations used in the CFD analysis in this paper are shown in details in Table 1.

Table 1: Details of equations used in the CFD simulations.

\begin{tabular}{|c|c|c|c|}
\hline $\begin{array}{c}\text { Description } \\
\text { [reference] }\end{array}$ & Phase & Equation & Notes \\
\hline Volume equation [31] & Gas & $V_{g}=\int_{V} \alpha_{g} d V$ & Equations of $V_{g}$ and $V_{l}$ \\
\hline
\end{tabular}




\begin{tabular}{|c|c|c|c|}
\hline & Liquid & $V_{l}=\int_{V} \alpha_{l} d V$ & must satisfy: $\alpha_{g}+\alpha_{l}=1$ \\
\hline \multirow{2}{*}{$\begin{array}{l}\text { Continuity equation in } \\
\text { 2D Cartesian } \\
\text { coordinates }(x, y)[32]\end{array}$} & Gas & $\frac{\partial v_{x, g}}{\partial x}+\frac{\partial v_{y, g}}{\partial y}=0$ & \\
\hline & Liquid & $\frac{\partial v_{x, l}}{\partial x}+\frac{\partial v_{y, l}}{\partial y}=0$ & \\
\hline \multirow{4}{*}{$\begin{array}{l}\text { Momentum equation in } \\
\text { 2D Cartesian } \\
\text { coordinates [33] }\end{array}$} & $\begin{array}{c}\text { Gas } \\
\underline{x-} \\
\text { direction } \\
\end{array}$ & $\begin{array}{c}\rho_{g} \alpha_{g}\left(\frac{\partial v_{x}}{\partial t}+v_{x} \frac{\partial v_{x}}{\partial x}+v_{y} \frac{\partial v_{x}}{\partial y}\right)=-\alpha_{g} \frac{\partial P}{\partial x}+ \\
\alpha_{g} \frac{\mu_{g, e f f}}{3} \frac{\partial(\nabla . V)}{\partial x}+\mu_{g, e f f} \alpha_{g}\left[\frac{\partial^{2} v_{x}}{\partial x^{2}}+\frac{\partial^{2} v_{x}}{\partial y^{2}}\right]+\rho_{g} \alpha_{g} g_{x}+ \\
M_{i, g, x}\end{array}$ & \\
\hline & $\begin{array}{c}\text { Gas } \\
y- \\
\text { direction } \\
\end{array}$ & $\begin{array}{c}\rho_{g} \alpha_{g}\left(\frac{\partial v_{y}}{\partial t}+v_{x} \frac{\partial v_{y}}{\partial x}+v_{y} \frac{\partial v_{y}}{\partial y}\right)=-\alpha_{g} \frac{\partial P}{\partial y}+ \\
\alpha_{g} \frac{\mu_{g, e f f}}{3} \frac{\partial(\nabla . V)}{\partial y}+\mu_{g, e f f} \alpha_{g}\left[\frac{\partial^{2} v_{y}}{\partial x^{2}}+\frac{\partial^{2} v_{y}}{\partial y^{2}}\right]+\rho_{g} \alpha_{g} g_{y}+ \\
M_{i, g, y}\end{array}$ & \\
\hline & $\begin{array}{l}\text { Liquid } \\
\underline{x-} \\
\text { direction } \\
\end{array}$ & $\begin{array}{c}\rho_{l} \alpha_{l}\left(\frac{\partial v_{x}}{\partial t}+v_{x} \frac{\partial v_{x}}{\partial x}+v_{y} \frac{\partial v_{x}}{\partial y}\right)=-\alpha_{l} \frac{\partial P}{\partial x}+ \\
\alpha_{l} \frac{\mu_{l, e f f}}{3} \frac{\partial(\nabla . V)}{\partial x}+\mu_{l, e f f} \alpha_{l}\left[\frac{\partial^{2} v_{x}}{\partial x^{2}}+\frac{\partial^{2} v_{x}}{\partial y^{2}}\right]+\rho_{l} \alpha_{l} g_{x}+ \\
M_{i, l, x}\end{array}$ & \\
\hline & $\begin{array}{c}\text { Liquid } \\
y- \\
\text { direction } \\
\end{array}$ & $\begin{array}{c}\rho_{l} \alpha_{l}\left(\frac{\partial v_{y}}{\partial t}+v_{x} \frac{\partial v_{y}}{\partial x}+v_{y} \frac{\partial v_{y}}{\partial y}\right)=-\alpha_{l} \frac{\partial P}{\partial y}+ \\
\alpha_{l} \frac{\mu_{l, e f f}}{3} \frac{\partial(\nabla . V)}{\partial y}+\mu_{l, e f f} \alpha_{l}\left[\frac{\partial^{2} v_{y}}{\partial x^{2}}+\frac{\partial^{2} v_{y}}{\partial y^{2}}\right]+\rho_{l} \alpha_{l} g_{y}+ \\
M_{i, l, y}\end{array}$ & \\
\hline \multirow{2}{*}{ Effective density } & Gas & $\hat{\rho}_{g}=\alpha_{g} \rho_{g}$ & \\
\hline & Liquid & $\hat{\rho}_{l}=\alpha_{l} \rho_{l}$ & \\
\hline \multirow{2}{*}{$\begin{array}{l}\text { Effective dynamic } \\
\text { viscosity }[22,34]\end{array}$} & Gas & $\hat{\mu}_{g}=\frac{\rho_{g}}{\rho_{l}} \hat{\mu}_{l}$ & $\begin{array}{l}\text { For } k-\epsilon \text { turbulence } \\
\text { model }\end{array}$ \\
\hline & Liquid & $\hat{\mu}_{l}=\mu_{\text {lam }, l}+\mu_{\text {tur }, l}+\mu_{B I T, l}$ & \\
\hline $\begin{array}{l}\text { Total interfacial force } \\
\text { acting between the } \\
\text { phases [31] }\end{array}$ & & $M_{i, l}=-M_{i, g}=M_{D}$ & $\begin{array}{l}\text { It is obtained by } \\
\text { neglecting the lift force } \\
\text { [18] and the virtual mass } \\
\text { force [36] }\end{array}$ \\
\hline Drag force [31] & & $M_{D}=\frac{\rho_{g} f}{6 \tau_{h}} d_{b} A_{i}\left(\boldsymbol{V}_{\boldsymbol{g}}-\boldsymbol{V}_{\boldsymbol{l}}\right)$ & For gas-liquid system \\
\hline Interfacial area [31] & & $A_{i}=\frac{6 \alpha_{g}\left(1-\alpha_{g}\right)}{d_{b}}$ & \\
\hline $\begin{array}{l}\text { Particular relaxation } \\
\text { time [31] }\end{array}$ & & $\tau_{b}=\frac{\rho_{g} d_{b}^{2}}{18 \mu_{l}}$ & \\
\hline Drag function [31] & & $f=\frac{C_{D} R e}{24}$ & \\
\hline Reynolds number [31] & & $R e=\frac{\rho_{l}\left|V_{g}-V_{l}\right| d_{b}}{\mu_{l}}$ & $\begin{array}{l}\left|\boldsymbol{V}_{\boldsymbol{g}}-\boldsymbol{V}_{\boldsymbol{l}}\right|: \text { slip velocity } \\
d_{b}: \text { Sauter-mean diameter }\end{array}$ \\
\hline $\begin{array}{c}\text { Schiller-Naumann drag } \\
\text { equation [36] }\end{array}$ & & $C_{D}= \begin{cases}\frac{24\left(1+0.15 R e_{b}^{0.687}\right)}{R e_{b}} & R e_{b} \leq 1000 \\
0.44 & R e_{b}>1000\end{cases}$ & \\
\hline
\end{tabular}


In the modelling of turbulence, the model that is usually used because of its accuracy is the standard $k-\varepsilon$ model. It solves two transport equations separately in which the turbulent velocity and length scales are determined independently. In the derivation of the standard $k-\varepsilon$ model, the molecular viscosity was neglected and the flow was assumed to be fully turbulent [31]. On the other hand, $k-\omega$ model shows better performance for low Reynolds number flows, but the negative aspect of this model is its relatively strong sensitivity of the solution to the values of $k$ and $\omega$ outside the shear layer (free stream sensitivity). For this reason, the use of the standard $k-\omega$ model is not generally recommended in ANSYS FLUENT [31]. For multiphase systems with high density ratio between gas and liquid phases such the system of this paper, two sub models can be used in the standard $k-\varepsilon$ turbulence model: the dispersed turbulence model, and a per-phase turbulence model [31]. In this paper, the dispersed turbulence model is used to model the turbulence in the bubble column, because of its less computational efforts [31]. The wall functions that have been most widely used in industrial flows, are the standard wall functions [31]. They are reasonably accurate for most of high-Reynolds-number flows with wall bound. In standard wall functions, the meshes created near the wall must be very fine to achieve the value of $y+$ within the log-law layer of the boundary layer (i.e. $30 \leq y+\leq 300$ ) [26]. In this paper, the standard wall functions are used.

In this paper, the 2D-CFD analysis of the BC is studied using the ANSYS FLUENT V.13 software. The overall diameter of the $\mathrm{BC}$ is taken to be $21.6 \mathrm{~cm}$ and height of static liquid of the $\mathrm{BC}$ is taken to have three different values (45, 55, and $65 \mathrm{~cm}$ ). First, ANSYS WORKBENCH V.13 was implemented to draw 2D geometries of the BC and to create meshing. Quadratic mapped mesh is used for the area of the BC and a very fine mesh is used near the wall. The size of the mesh is selected so that there is no dependence of the gas holdup $\left(\alpha_{g}\right)$ on grid. After investigating the grids for different $H$ and $U_{g s}$, it has been found that the most unfavourable situation is for $H=65 \mathrm{~cm}$ and $U_{g s}=0.15 \mathrm{~m} / \mathrm{s}$. Table 2 shows the grid independence study that was used to select the optimum grid distribution of the BC problem. From Table 2, it can be seen that the optimum grid is when the number of cells is 20,203 cells, because this will provide minimum relative errors of $0.43 \%$ for the values of $\alpha_{g}$, when compared with the grid of 56,341 cells. When using the grid of 56,341 cells, the memory requirement of the computer as well as the calculation time will increase significantly because the number of cells is more than twice of that of 20,203. Since the relative errors of $\alpha_{g}$ between the two grids are very small, it is preferred to use the grid of 20,203 cells and reduce the memory requirement of the computer and the calculation time. The quantity of interest that is monitored during the CFD simulation is the overall gas holdup. The convergence criteria of the simulation is to ensure that the quantity of interest reached a steady state simulation and the residual RMS error values were less than $10^{-}$

${ }^{4}$. Table 3 summarizes the setup of the BC problem in ANSYS FLUENT.

Table 2: Grid independence test for a helium-water BC $\left(H=65 \mathrm{~cm}, U_{g s}=0.15 \mathrm{~m} / \mathrm{s}\right)$.

\begin{tabular}{|c|c|c|c|c|}
\hline $\begin{array}{c}\text { Total } \\
\text { Cells }\end{array}$ & 3,704 & 20,203 & 34,288 & $\begin{array}{c}56,34 \\
1\end{array}$ \\
\hline$\alpha_{g}(\%)$ & 22.3 & 23 & 22.8 & 23.1 \\
\hline
\end{tabular}

Table 3: Summary of the BC problem setup in ANSYS FLUENT.

\begin{tabular}{|l|l|l|}
\hline \multirow{4}{*}{ General } & Solver Type & Pressure-Based \\
\cline { 2 - 3 } & Velocity Formulation & Absolute \\
\cline { 2 - 3 } & Time & Steady \\
\cline { 2 - 3 } & Gravity & ON \\
\cline { 2 - 3 } & $2 D$ Space & Planar \\
\hline \multirow{4}{*}{ Models } & Multiphase-Eulerian \\
\cline { 2 - 3 } & Energy-On \\
\cline { 2 - 3 } & Viscous-Standard $k-\varepsilon$, Standard Wall Function, Dispersed \\
\hline Materials & Water liquid \\
\hline
\end{tabular}




\begin{tabular}{|c|c|c|c|}
\hline & \multicolumn{3}{|l|}{ Helium gas } \\
\hline \multirow{2}{*}{ Phases } & \multicolumn{3}{|c|}{ Primary phase=liquid phase } \\
\hline & \multicolumn{3}{|c|}{ Secondary Phase $=$ gas phase } \\
\hline Bubble Diameter & \multicolumn{3}{|c|}{ Sauter-mean diameter } \\
\hline \multirow{8}{*}{ Solution Methods } & Scheme & \multicolumn{2}{|l|}{ Phase-Coupled SIMPLE } \\
\hline & \multirow{7}{*}{ Spatial Discretization } & Gradient & Least Squares Cell Based \\
\hline & & Momentum & Second Order Upwind \\
\hline & & Volume Fraction & First Order Upwind \\
\hline & & Turbulent Kinetic Energy & Second Order Upwind \\
\hline & & Turbulent Dissipation Rate & Second Order Upwind \\
\hline & & Energy & Second Order Upwind \\
\hline & & Interfacial Area Concentration & Second Order Upwind \\
\hline
\end{tabular}

The boundary conditions of the BC can be represented by inlet, outlet and wall boundary conditions. The inlet volume fraction of the gas is equal to 1 and the inlet velocity of the gas is considered uniform and equal to the volumetric flow rate of the gas divided by the total cross-sectional area of the sparger's orifices. According to Akhtar et al. (2006), the pressure boundary condition can be applied at the outlet of the column because it will produce better convergence. In all simulations, the outlet pressure is equal to atmospheric pressure. The no-slip boundary conditions are applied at the walls of the BC. Symmetry conditions were not used in the simulations to be able to obtain better behaviors of hydrodynamics. Because of the estimation difficulty of the liquid turbulence at the inlet and outlet boundary conditions of the liquid phase, iterations were used to specify the turbulent kinetic energy and dissipation rate.

\section{Results}

In this section, the CFD models results of the hydrodynamic studies for steady-state conditions are introduced. The effects of superficial gas velocities $\left(U_{g s}\right)$, and static liquid heights $(H)$ on gas holdup are investigated.

\subsection{Effects of Superficial Gas Velocity $\left(U_{g s}\right)$ and Static Liquid Height $(H)$ on $\alpha_{g}$}

Figures 1-3 show the effect of superficial gas velocity $\left(U_{g s}\right)$ and static liquid height $(H)$, on the numerical overall gas holdup $\left(\alpha_{g}\right)$ of the helium-water BC. From these figures, it can be seen that $\alpha_{g}$ increases by increasing $U_{g s}$ and/or decreasing $H$. Figs. 4 and 5 show the effect of $U_{g s}$ and $H$ on the contours of $\alpha_{g}$. It can be seen in these figures that the radial distribution of the gas holdup is unequal, where the gas holdup is high in the center and low in the wall region. This behavior is due to the gradient of buoyancy forces between the column center and the wall region as indicated by Shaikh and Al-Dahhan [37].

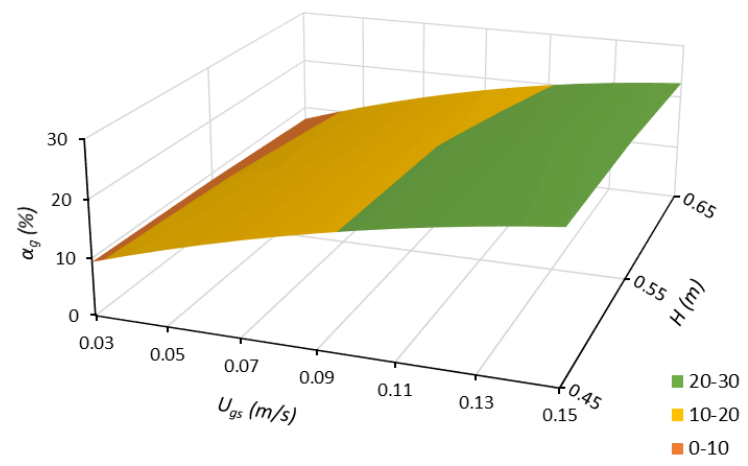

Fig. 1: Numerical overall gas holdup versus $U_{g s}$ and $H$ of helium-water BC. 


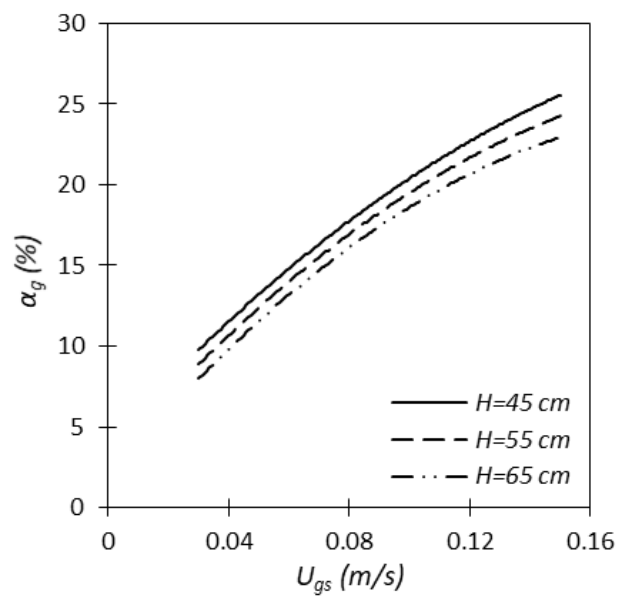

Fig. 2: Effect of static liquid height on numerical $\alpha_{g}$ versus $U_{g s}$ of helium-water BC.
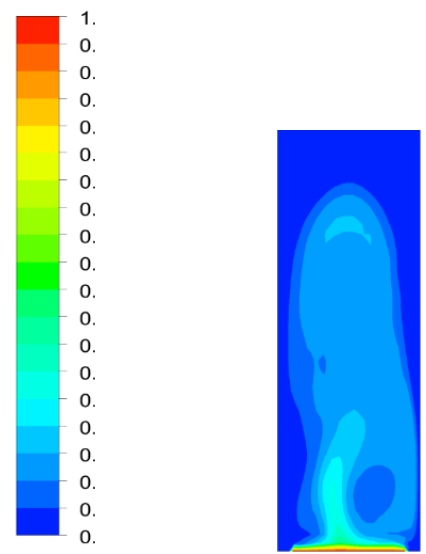

$$
U_{g s}=0.05 \mathrm{~m} / \mathrm{s}
$$

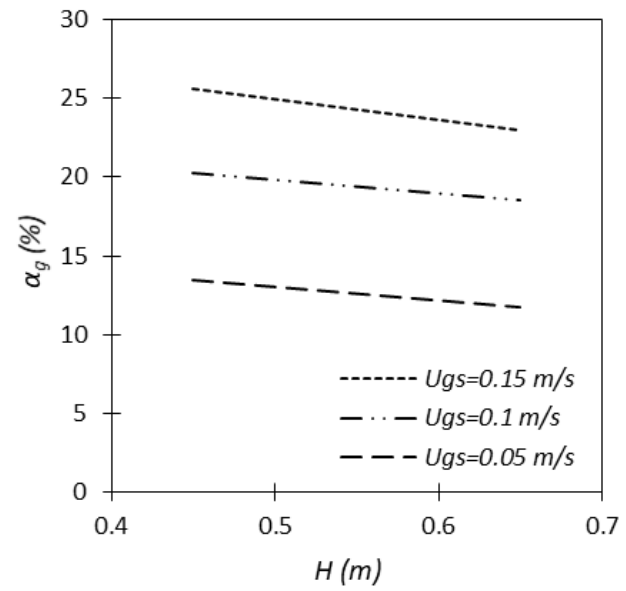

Fig. 3: Numerical overall gas holdup versus $H$ of helium-water BC for different $U_{g s}$.
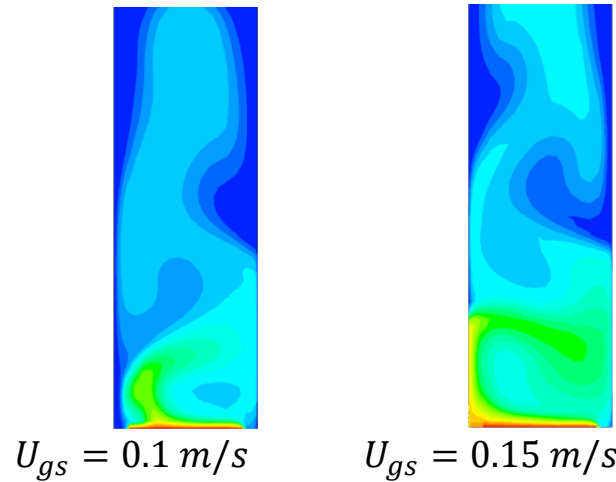

$U_{g s}=0.15 \mathrm{~m} / \mathrm{s}$

Fig. 4: Contours of gas holdup of a helium-water BC, $H=65 \mathrm{~cm}$ and different $U_{g s}$.
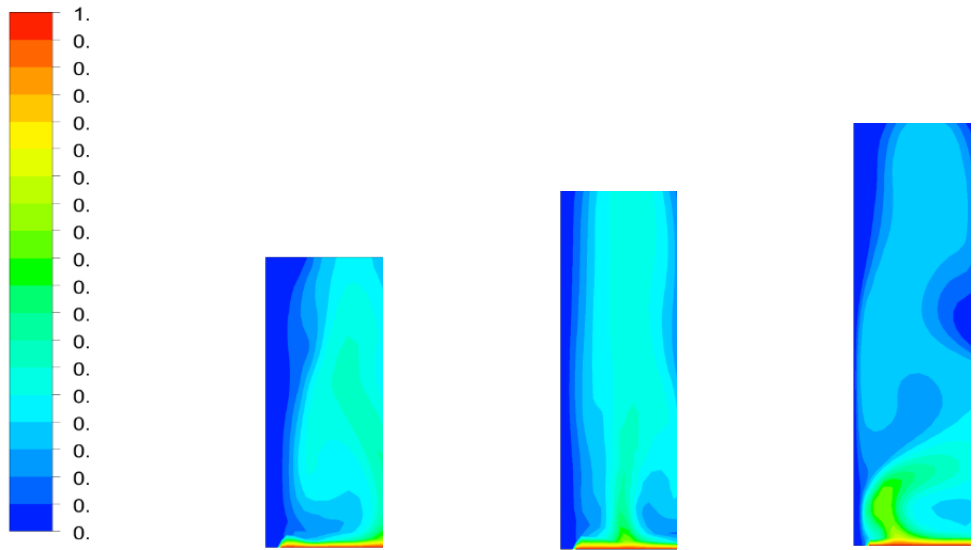

$$
H=45 \mathrm{~cm}
$$

$H=55 \mathrm{~cm}$

$$
H=65 \mathrm{~cm}
$$

Fig. 5: Contours of $\alpha_{g}$ of a helium-water BC, $U_{g s}=0.1 \mathrm{~m} / \mathrm{s}$ and different $H$. 


\subsection{Comparison of Numerical $\alpha_{g}$ with the Experimental Data}

To validate the numerical (CFD) data of hydrodynamic studies produced in the helium-water BC, a comparison is made with the experimental data of Abdulrahman [8 12]. Fig. 6 compares between the CFD simulations and experimental results of $\alpha_{g}$ versus $U_{g s}$ for different $H$. In general, it can be seen that all profiles of $\alpha_{g}$ calculated from CFD models under-predict the experimental data with a maximum relative error of less than $28.5 \%$. Considering the complexity of the multi-phase flow in bubble columns, the agreement is satisfactory and encouraging. The reduction in the results of CFD models is caused by the use of a 2D-plane mesh producing lower gas flow rates when compared with the 3D column. Also, the CFD model applied the source for the gas phase across the base of the column, ignoring the effect of the sparger height and therefore over-estimating the static liquid height $(H)$. Due to that, the overall gas holdup is under-estimated when compared with the experimental flows. Another reason for the reduction of $\alpha_{g}$ is that the turbulent nature of the flow demands the use of a very fine mesh to realize all the vortical structures in the flow, especially for the smaller eddies [23]. The ability of the CFD model to account for $H$ effect on $\alpha_{g}$ versus $U_{g s}$ is also assessed by comparison to the experimental data of Abdulrahman $[8,12]$ as shown in Figs. 7 and 8. Fig. 7 shows that, the curves of $\alpha_{g}$ versus $U_{g s}$ at different values of $H$, are approximately parallel to each other, which means that the values of $\alpha_{g}$ versus $U_{g s}$ decreases almost with a constant value by increasing $H$. In other words, the rate of decrease of $\alpha_{g}$ versus $H$ is higher at lower $U_{g s}$. This behavior of $\alpha_{g}$ versus $U_{g s}$ is also shown in Fig. 8 with $\alpha_{g}$ versus $H$, where the curves are approximately parallel to each other for different values of $U_{g s}$. The above experimental behaviors of $\alpha_{g}$ versus $U_{g s}$ and $H$ are correctly predicted by the CFD model.
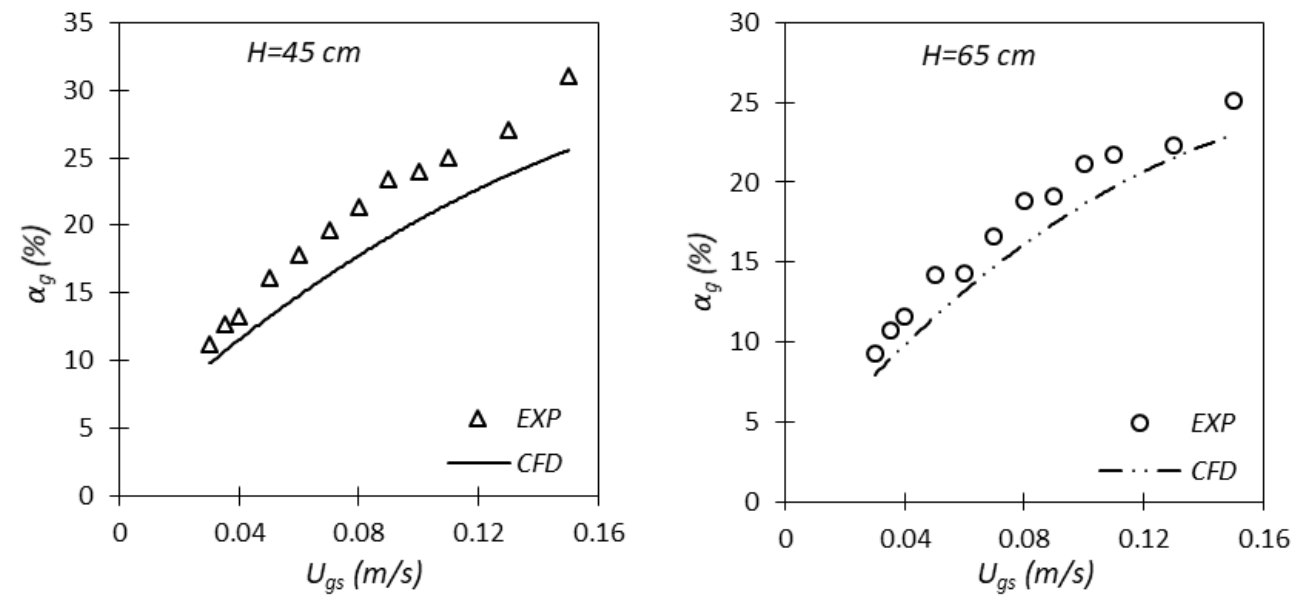

Fig. 6: Comparison of $\alpha_{g}$ versus $U_{g s}$ between CFD and experimental results for different $H$ of helium-water BC. 


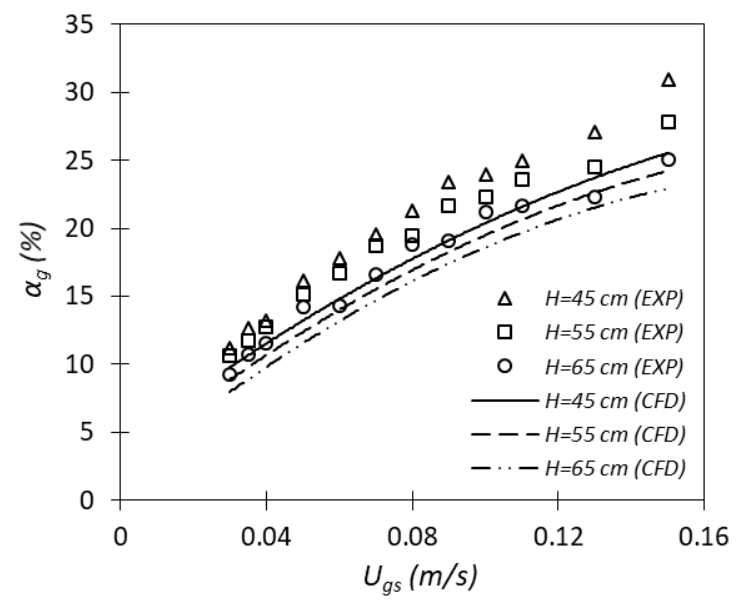

Fig. 7: Effect of $H$ on $\alpha_{g}$ versus $U_{g s}$ of helium-water BC for experimental data and CFD model.

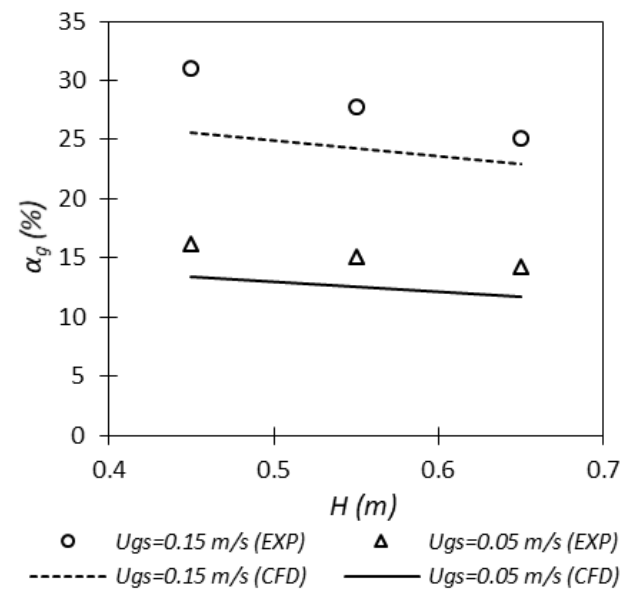

Fig. 8: Comparison between CFD and experimental $\alpha_{g}$ versus $H$ of helium-water BC for different $U_{g s}$.

\section{Conclusion}

Two dimensional CFD simulations of helium-water system were developed to predict the values of the gas hold-up at different superficial gas velocities, and static liquid heights. In this paper, the multiphase Euler-Euler method was used for the numerical solutions and the standard $k-\varepsilon$ dispersed turbulence model was used for modeling the turbulence in the bubble column. The data of gas holdup were validated against the experimental data and showed good agreement. The validation of the CFD simulations with the experimental data demonstrates the applicability of the simulations for the helium-water bubble column systems. The CFD simulations were validated for superficial gas velocities up to $0.15 \mathrm{~m} / \mathrm{s}$, and aspect ratios up to 4 . From the CFD simulations, the following points are concluded;

a) In general, the profiles of $\alpha_{g}$ determined from CFD simulations, under-predicted the experimental data.

b) The experimental effect of $H$ on $\alpha_{g}$ was correctly predicted by CFD simulations.

c) The distribution of gas holdup along the cross-section of the column is unequal, where the gas holdup is higher at the center of the column and lower near the wall region.

\section{Nomenclature}

\begin{tabular}{|c|l|c|l|}
\hline Symbol & \multicolumn{1}{|c|}{ Definition } & Symbol & \multicolumn{1}{|c|}{ Definition } \\
\hline$A_{i}$ & Interfacial area $\left(\mathrm{m}^{2}\right)$ & $\boldsymbol{V}_{\boldsymbol{g}}$ & Velocity field of gas phase (m/s) \\
$C_{D}$ & Drag coefficient & $\boldsymbol{V}_{\boldsymbol{l}}$ & Velocity field of slurry phase (m/s) \\
$d_{b}$ & Bubble diameter $(\mathrm{m})$ & $\alpha_{g}$ & Gas holdup \\
$f$ & Drag function & $\alpha_{l}$ & Liquid holdup \\
$g$ & Gravitational acceleration $\left(\mathrm{m}^{2} / \mathrm{s}\right)$ & $\mu_{e f f}$ & Effective dynamic viscosity (Pa.s) \\
$H$ & Height of static liquid $(\mathrm{m})$ & $\mu_{g}$ & Dynamic viscosity of gas phase (Pa.s) \\
$M_{D}$ & Drag force $\left(\mathrm{N} / \mathrm{m}^{3}\right)$ & $\mu_{l}$ & Dynamic viscosity of liquid phase (Pa.s) \\
$M_{i}$ & Total interfacial force acting between phases $\left(\mathrm{N} / \mathrm{m}^{3}\right)$ & $\hat{\mu}_{g}$ & Effective dynamic viscosity of phase (Pa.s) \\
$P$ & Pressure $(P a)$ & $\hat{\mu}_{l}$ & Effective dynamic viscosity of liquid \\
& & & (Pa.s) \\
$R e$ & Reynolds number & $\mu_{l a m, l}$ & Molecular viscosity (Pa.s) \\
$U_{g s}$ & Superficial velocity of gas $(\mathrm{m} / \mathrm{s})$ & $\mu_{t u r, l}$ & Shear-induced turbulent viscosity (Pa.s) \\
$v_{x, g}$ & Velocity component in $x$-direction of gas phase $(\mathrm{m} / \mathrm{s})$ & $\mu_{B I T, l}$ & Bubble-induced turbulence viscosity (Pa.s) \\
& & & \\
\hline
\end{tabular}




\begin{tabular}{|c|l|c|l|}
\hline$v_{x, l}$ & $\begin{array}{l}\text { Velocity component in } x \text {-direction of slurry phase } \\
(\mathrm{m} / \mathrm{s})\end{array}$ & $\rho$ & Density $\left(\mathrm{kg} / \mathrm{m}^{3}\right)$ \\
$v_{y, g}$ & Velocity component in $y$-direction of gas phase $(\mathrm{m} / \mathrm{s})$ & $\rho_{g}$ & Density of gas $\left(\mathrm{kg} / \mathrm{m}^{3}\right)$ \\
\hline Symbol & \multicolumn{1}{|c|}{ Definition } & Symbol & Definition \\
\hline$v_{y, l}$ & Velocity component in $y$-direction of slurry phase & $\rho_{l}$ & Density of liquid $\left(\mathrm{kg} / \mathrm{m}^{3}\right)$ \\
$V_{g}$ & Volume of gas phase $\left(\mathrm{m}^{3}\right)$ & $\hat{\rho}_{g}$ & Effective density of gas phase $\left(\mathrm{kg} / \mathrm{m}^{3}\right)$ \\
$V_{l}$ & Volume of liquid phase $\left(\mathrm{m}^{3}\right)$ & $\hat{\rho}_{l}$ & Effective density of liquid phase $\left(\mathrm{kg} / \mathrm{m}^{3}\right)$ \\
$V_{S}$ & Volume of solid phase $\left(\mathrm{m}^{3}\right)$ & $\tau_{b}$ & Particulate relaxation time $(\mathrm{s})$ \\
\hline
\end{tabular}

\section{References}

[1] Y. T. Shah, B. G. Kelkar, S. P. Godbole, and W. D. Deckwer, "Design parameters estimations for bubble column reactors," American Institute of Chemical Engineers Journal, vol. 28, pp. 353-379, 1982.

[2] A. Shaikh, "Bubble and slurry bubble column reactors: mixing, flow regime transition and scale-up," $\mathrm{Ph} . \mathrm{D}$. dissertation, Sever Institute of Washington University, Saint Louis, Missouri, USA, 2007.

[3] K. Nigar, B. Fahir, and O. U. Kutlu, "Review: Bubble column reactors," Process Biochemistry, vol. 40, pp. 2263-2283, 2005.

[4] W. D. Deckwer, Y. Louisi, A. Zaidi, and M. Ralek, "Hydrodynamic properties of the Fisher-Tropsch slurry process," Industrial \& Engineering Chemistry Process Design and Development, vol.19, pp. 699-708, 1980.

[5] C. Guy, J. P. Carreau, and J. Paris, "Mixing characteristics and gas holdup of a bubble column," The Canadian Journal of Chemical Engineering, vol. 64, no. 1, pp. 23-35, 1986.

[6] S. C. Saxena, and Z. D. Chen, "Hydrodynamics and heat transfer of baffled and unbaffled slurry bubble column," Reviews in Chemical Engineering, vol. 10, no. 3-4, pp. 193-400, 1994.

[7] A. Behkish, "Hydrodynamic and mass transfer parameters in large-scale slurry bubble column reactors," $\mathrm{Ph} . \mathrm{D}$. dissertation, University of Pittsburgh, Pennsylvania, USA, 2004.

[8] M. W. Abdulrahman, "Experimental studies of gas holdup in a slurry bubble column at high gas temperature of a helium- water- alumina system," Chemical Engineering Research and Design, vol.109, pp. 486-494, 2016.

[9] M. W. Abdulrahman, "Experimental studies of the transition velocity in a slurry bubble column at high gas temperature of a helium-water-alumina system," Experimental Thermal and Fluid Science, vol. 74, pp. 404410, 2016.

[10] M. W. Abdulrahman, "Experimental studies of direct contact heat transfer in a slurry bubble column at high gas temperature of a helium-water-alumina system," Applied Thermal Engineering, vol. 91, pp. 515-524, 2015.

[11] M. W. Abdulrahman, "Direct contact heat transfer in the thermolysis reactor of hydrogen production cu-cl cycle," US Patent 10059 586, August 28, 2018.

[12] M. W. Abdulrahman, "Analysis of the thermal hydraulics of a multiphase oxygen production reactor in the $\mathrm{Cu}-$ Cl cycle,” Ph.D. dissertation, UOIT, Ontario, Canada, 2016.

[13] C. Chen, and L. S. Fan, "Discrete simulation of gas-liquid bubble columns and gas-liquid-solid fluidized beds," American Institute of Chemical Engineers Journal, vol. 50, pp. 288-301, 2004.

[14] H. A. Jakobsen, B. H. Sannaes, S. Grevskott, and H. F. Svendsen, "Modelling of vertical bubble-driven flows," Industrial \& Engineering Chemistry Research, vol. 36, pp. 4052-4074, 1997.

[15] J. B. Joshi, "Computational flow modelling and design of bubble column reactors," Chemical Engineering Science, 56, 5893-5933. (2001).

[16] J. B. Joshi, V. S. Vitankar, A. A. Kulkarni, M. T. Dhotre, and K. Ekambara, "Coherent flow structures in bubble column reactors," Chemical Engineering Science, vol. 57, pp. 3157-3183, 2002.

[17] S. La1'n, D. Bröder, M. Sommerfeld, and M. F. Göz, "Modelling hydrodynamics and turbulence in a bubble column using the Euler-Lagrange procedure," International Journal of Multiphase Flow, vol. 28, pp. 13811407, 2002. 
[18] A. Sokolichin, G. Eigenberger, and A. Lapin, "Simulation of buoyancy driven bubbly flow: Established simplifications and open questions," American Institute of Chemical Engineers Journal, vol. 50, pp. 24-45, 2004.

[19] E. Delnoij, J. A. M. Kuipers, and W. P. M. van Swaaij, "Computational fluid dynamics applied to gas-liquid contactors," Chemical Engineering Science, vol. 52, pp. 3623-3638, 1997a.

[20] E. Delnoij, J. A. M. Kuipers, and W. P. M. van Swaaij, "Dynamic simulation of gas-liquid two-phase flow: Effect of column aspect ratio on the flow structure," Chemical Engineering Science, vol. 52, pp. 3759-3772, 1997b.

[21] E. Delnoij, F. A. Lammers, J. A. M. Kuipers, and W. P. M. van Swaaij, "Dynamic simulation of dispersed gasliquid two-phase flow using a discrete bubble model," Chemical Engineering Science, vol. 52, pp. 1429-1458, $1997 \mathrm{c}$.

[22] M. M. Sarah, S. V. Vivek, and O. F. Rodney, "CFD predictions for flow-regime transitions in bubble columns," American Institute of Chemical Engineers Journal, vol. 51, no. 7, pp. 1897-1923, 2005.

[23] A. Sokolichin, and G. Eigenberger, "Applicability of the standard $k-\varepsilon$ turbulence model to the dynamic simulation of bubble columns: Part I. Detailed numerical simulations," Chemical Engineering Science, vol. 54, pp. 2273-2284, 1999.

[24] N. G. Deen, T. Solberg, and B. H. Hjertager, "Large eddy simulation of gas-liquid flow in a square crosssectioned bubble column," Chemical Engineering Science, vol. 56, pp. 6341-6349, 2001.

[25] R. Krishna, J. M. van Baten, M. I. Urseanu, and J. Ellenberger, "Design and scale-up of the bubble column slurry reactor for Fischer-Tropsch synthesis," Chemical Engineering Science, vol. 56, no. 2, pp. 537-545, 2001.

[26] M. W. Abdulrahman, "CFD simulations of direct contact volumetric heat transfer coefficient in a slurry bubble column at a high gas temperature of a helium-water-alumina system," Applied Thermal Engineering, vol. 99, pp. 224-234, 2016.

[27] M. W. Abdulrahman, "CFD Analysis of Temperature Distributions in a Slurry Bubble Column with Direct Contact Heat Transfer," in proceedings of the 3rd International Conference on Fluid Flow, Heat and Mass Transfer (FFHMT'16), Ottawa, ON, Canada, 2016.

[28] D. Law, F. Battaglia, and T. Heindel, "Numerical simulations of gas-liquid flow dynamics in bubble columns," In: Proceedings of 2006 ASME International Mechanical Engineering Congress and Exposition, Chicago, Illinois, USA, 2006, pp. 593-600.

[29] M. Rampure, V. Buwa, and V. Ranade, "Modelling of gas-liquid/gas-liquid-solid flows in bubble columns: Experiments and CFD simulations," The Canadian Journal of Chemical Engineering, vol. 81, no. 3-4, pp. $692-$ 706, 2003.

[30] A. F. Studely, "Numerical Modeling of Air-Water Flows in Bubble Columns and Airlift Reactors," Master's Thesis), Virginia Polytechnic Institute and State University, Blacksburg, Virginia, 2010.

[31] ANSYS, ANSYS FLUENT Theory Guide. Release 14.5. ANSYS, Inc, 2012.

[32] A. Bejan, Convection heat transfer ( $3^{\text {rd }}$ ed.). John Wiley \& sons, Inc., 2004.

[33] G. K. Batchelor, (1967), An introduction to fluid dynamics. Cambridge University Press, Cambridge, England, 1967.

[34] V. Mahajan, "CFD analysis of hydrodynamics and mass transfer of a gas-liquid bubble column," Bachelor's project, Rourkela, Orissa, India, 2010.

[35] M. Rafique, P. Chen, P., and M. P. Duduković, "Computational modeling of gas-liquid flow in bubble columns," Reviews in Chemical Engineering, vol. 20, no. 3-4, pp. 225-375, 2004.

[36] L. Schiller, and A. Naumann, "Uber die grundlegenden berechnungen bei der schwerkraftaufbereitung / About the basic calculations in the gravity-treatment. Zeitung des vereins deutscher ingenieure / Newspaper of the Association of German Engineers, 1933, pp. 77-318.

[37] A. Shaikh, and M. H. Al-Dahhan, "A review on flow regime transition in bubble columns," International Journal of Chemical Reactor Engineering, vol. 5, Review R1, 2007. 